\title{
The effect of Extreme Low Frequency-Pulsed Electromagnetic Field exposure in the healing process of Sprague Dawley mouse delayed union femur fracture: study of Rust Radiology Score
}

\author{
Ismail, Andika D Djaja*, Ronald H Tendean \\ Department of Orthopaedics and Traumatology, Cipto Mangunkusumo Hospital - Faculty of \\ Medicine Universitas Indonesia, Jakarta, Indonesia \\ *Corresponding author: andika_dwiputra@rocketmail.com
}

\begin{abstract}
Fractures usually heal normally. In some conditions, the healing process do not occur normally, but become delayed union or non union as a complication. Successful healing of fractures is a complex interaction between the process of angiogenesis and osteogenesis (the interaction of osteoblasts and osteoclast). Physical stimuli such as exposure of EMF (electromagnetic fields) influences of the osteogenesis process both in the development stage of embryo reinforcement and the fracture healing stage. The aim of this study is to determine the healing of delayed union fractures in experimental animals due to the expossure of Extreme Low Frequency-Pulsed Electromagnetic Field (ELF-EMF) by comparing the RUST scores. The experimental study was conducted Department of Nutrition Animal Laboratory, Faculty of Medicine, Universitas Indonesia with 56 experimental rats during AugustSeptember 2018. There were no differences of animal characteristics in the study. It was found that there were significant differences in Rust Score in the treatment and control groups in each examination week. There were no differences in clinical improvement in the two groups. This study concluded that there was an improvement in delayed union fracture healing after the administration of ELF-EMF as seen from the difference in Rust score.
\end{abstract}

Key words: Extreme Low Frequency-Pulsed Electromagnetic Field, delayed union fracture, Rust score

\section{INTRODUCTION}

Fractures may occur in productive ages and become one of the most common causes of injury in traffic accidents (Riyadina et al., 2009; Singer et al., 1998; Ganveer and Tiwari, 2005). In Indonesia, about 9,1\% of fractures are caused by traffic accidents (Riyadina et al., 2009). During his life, a person has a $50 \%$ risk of fracture (Brinker and O'Connor, 2004). Generally, fractures can heal normally but in some cases, healing fractures do not occur normally. In these cases, some complications

may occur such as delayed union or non-union. In previous studies, the prevalence of non-union events was $2.5 \%$ and delayed union was $4.4 \%$. Other studies concluded that the prevalence of delayed union cases in open tibia fractures is 31\% (Phieffer and Goulet, 2006). This abnormal bone healing process causes a variety of advanced problems such as joint arthritis, decreased joint mobility, immobilization and prolonged treatment and leads to a decrease in the quality of life of patients. 
An understanding of the diamond concept is important in the healing approach to bone fractures. Bone healing process consists of osteogenic (cell) components, osteoconductive (matrix, scaffold), osteoinductive (growth factors), stable mechanical/fixation environment, and vascularization (Giannoudis et al., 2007; Giannoudis et al., 2008). Each components influence one another so that the deficiency in one component causes disruption of the bone healing process can cause delayed union or non union (Lu et al., 2007).

Many studies have tried to find the effect of biophysical stimulation, including mechanical simulations, ultrasound, electrical and electromagnetic, with the fracture healing process. Electromagnetic field (EMF) stimulation in several studies has shown influence on the expression of osteogenic genes, but the mechanisms are not fully known yet (Teven et al., 2012; Einhorn and Gerstenfeld, 2015). Bone piezoelectricity or the bio-electric-mechanical phenomena is the main explanation of this mechanism. Mechanical stress to the bone will produce an endogenous electric field in the bone and collagen, an extra cellular component of bone, acts as a transducer, transforming mechanical energy into electricity. This endogenous electric field influences the biology of bone including cell proliferation, vascular invasion, facilitates classification, lowers oxygen pressure,

\section{MATERIALS AND METHODS}

An experimental test was done using 56 male Sprague-Dawley rats, weighted of 250300 grams randomly grouped into 2 groups. The study was carried out for 5 weeks with increases $\mathrm{pH}$, and changes the cyclic activity of AMP. All this mechanisms will promote osteogenesis (Bilezikian and Lawrence, 1996). Two main signaling pathways, WNT (winglessint) and BMP (bone morphogenetic protein), are hypothesized as the main processes of osteogenesis (Marcelini et al., 2012).

Various of research on the effects of EMF exposure has been widely carried out. In a study conducted in 2014 found that 28 days of EMF exposure combined with BMP-2 exposurd in culture cells caused a significant increase in alkaline phosphates activity and accelerated calcium deposit process, both of which are markers of osteogenesis (Ongaro et al., 2014; Fu et al., 2014). Another study found that there was better clinical improvement in the first 3 months in a group of patients with long bone fractures who experienced delayed union who received EMF stimulation (38.7\% compared to $22.2 \%$ ). At the end of treatment, a faster recovery rate was found in the group receiving EMF stimulation (77.4\% versus $48.1 \%)$ (Shirley et al., 2005).

This study aims to determine the effect of ELFEMF stimulation on bone healing process assessed from bone radiology examinations. This research was conducted to give consideration in biophysical therapy that can be used to support the existing fracture healing therapy modalities.

examination of 7 rats in the group receiving ELF-EMF stimulation and control groups. The protocol of the study had been approved by the Health Research Ethics Committee, Faculty of 
Medicine, University of Indonesia-Cipto Mangunkusumo Hospital. In each animal, a fracture is made and then fixed with intramedullary K-wire. A delayed union healing model is made by the circular periosterum stripping method, $5 \mathrm{~mm}$ from the fracture line to distal and proximal (Utvåg et al., 1996). During surgery, each rat received anesthesia with intraperitoneal injection of Ketamine 80 $\mathrm{mg} / \mathrm{kgBB}$ (Ilium Ketamil Injection ${ }^{\circledR}$, Troy laboratories PTY limited Australia) and Xylazine 10 mg/kgBB (Ilium Xylazil-100 Injection ${ }^{\circledR}$, Troy laboratories PTY limited Australia). Both groups were kept in the Animal Laboratory of Research and Development, Indonesian Ministry of Health.

In the intervention group, electromagnetic fields were given an intensity of 4 hours/day. At second, third, fourth and fifth weeks, the subjects was sacrifices with $75 \mathrm{~mm} / \mathrm{kgBB}$ phenobarbitas intraperitoneally. Each week 7 subjects was sacrificed in each group. Later, femur was cleaned from the surrounding muscle

\section{RESULTS}

The mean weight of subjects at the begining of the experiment was 269.70 grams. In the analysis with $\mathrm{T}$ test for unpaired samples, there were no differences in characteristics of tissue leaves the soft tissue around the fracture area. Specimens are stored in special containers. X-Ray examination was carried out in the Department of Radiology Faculty of Medicine, University of Indonesia-Cipto Mangunkusumo Hospital, given exposure to $52 \mathrm{kV}$ and $6.4 \mathrm{~mA}$ for 400 milliseconds with ventrodorsal and laterolateral projections in the left femur of the rat. The assessment was carried out radiologically on plain 2 projection photographs on the fracture line on the four sides of the cortex (anterior, posterior, medial and lateral) with a score of 4-12. The RUST score assessment is done blindly by Orthopedics. Statistical assessment was performed with SPSS by analyzing the test with one way ANOVA for data with normal distribution and Kruskal wallis test for data with abnormal distribution. If there is significance in the one way ANOVA test, then the Post Hoc analysis is used to assess the comparison between groups.

experimental animal weight, femur weight and femur length in the treatment group and control group. Characteristics of animal experiments are illustrated in the table below.

Tabel 1. Characteristic of Subjects

\begin{tabular}{cclll}
\hline Week & Variables & \multicolumn{1}{c}{$\begin{array}{c}\text { Intervention } \\
\mathrm{n}=7\end{array}$} & \multicolumn{1}{c}{$\begin{array}{c}\text { Control } \\
\mathrm{n}=7\end{array}$} & $\mathrm{p}$ value \\
\hline 1 & Weight $(\mathrm{g})$ & $286,04 \pm 41,72$ & $265,5 \pm 25,58$ & 0,389 \\
& Weight $(\mathrm{g})$ & $246,57 \pm 23,16$ & $265,43 \pm 39,30$ & 0,296 \\
2 & Femur weight $(\mathrm{g})$ & $1,21 \pm 0,12$ & $1,14 \pm 0,36$ & 0,625 \\
& Femur length $(\mathrm{cm})$ & $34,06 \pm 1,48$ & $35,57 \pm 1,52$ & 0,085 \\
3 & Weight $(\mathrm{g})$ & $247,14 \pm 21,97$ & $270,71 \pm 29,14$ & 0,113 \\
\hline
\end{tabular}




\begin{tabular}{cclll}
\hline & Femur weight $(\mathrm{g})$ & $1,50 \pm 0,25$ & $1,46 \pm 0,26$ & 0,793 \\
& Femur length $(\mathrm{cm})$ & $33,54 \pm 1,21$ & $34,67 \pm 1,38$ & 0,128 \\
& Weight $(\mathrm{g})$ & $283,29 \pm 40,99$ & $269,00 \pm 13,59$ & 0,399 \\
& Femur weight $(\mathrm{g})$ & $1,83 \pm 0,25$ & $1,68 \pm 0,29$ & 0,315 \\
& Femur length $(\mathrm{cm})$ & $34,71 \pm 1,99$ & $36,26 \pm 1,12$ & 0,099 \\
& Weight $(\mathrm{g})$ & $297,14 \pm 27,18$ & $280,00 \pm 28,08$ & 0,628 \\
& Femur weight $(\mathrm{g})$ & $1,70 \pm 0,39$ & $1,85 \pm 0,08$ & 0,186 \\
& Femur length $(\mathrm{cm})$ & $37,49 \pm 2,32$ & $36,22 \pm 1,49$ & 0,245 \\
\hline
\end{tabular}

There were significant differences of RUST Score values in both groups. The RUST Score in the experimental group are higher. Further analysis was carried out in the treatment group with One-Way ANOVA with Post Hoc Turkey. It was found that there was a statistically significant difference in the Rust score for each week.

Tabel 2. Comparison of RUST Score in both groups

\begin{tabular}{lccl}
\hline Week & $\begin{array}{c}\text { Intervention } \\
\mathrm{n}=7\end{array}$ & $\begin{array}{c}\text { Control } \\
\mathrm{n}=7\end{array}$ & $\mathrm{p}$ value* \\
\hline 2 & $6(5-7)$ & $4(4-5)$ & 0,002 \\
3 & $8(7-9)$ & $6(6-7)$ & 0,003 \\
4 & $9(9-11)$ & $8(8-10)$ & 0,016 \\
5 & $11(10-12)$ & $9(8-11)$ & 0,013 \\
\hline
\end{tabular}

* Mann-Whitney U test

\section{DISCUSSION}

This study involved 56 male Sprague Dawley rats aged 3-4 months and declared healthy. In this study there were no experimental animals that had infection in the trauma area and none had experienced implant protrusion and died during the trial. The mean rat weight at the start of the experiment was 269.70 grams. There were no mean differences in weight in the control and treatment group at the beginning of the study until the radiology examination was carried out. There were no differences in characteristics of femur weight and femur length in the two groups. Control of rat body weight during research is important because weight is one of the determinants factor of fracture healing in experimental animals. Obesity can slows the bone healing (Gao et al., 2018).

In the study, an assessment of healing of delayed union fractures on 4 phases was carried out in the 2nd to 5 th week. This follow the bone healing process involving the bone cortex, periosteum, connective tissue and bone marrow. The healing process for bone endochondral fracture starts from 7th to 10th day which is characterized by a condrogenesis process. On the 14th day, cartilage calcification is began and bone formation occur under 
periosterum. In the 3rd week the callus formed is formed mainly by calcified cartilage which is then degraded by condorblasts to be replaced by bone. Calcified trabeculae of bone and cartilage become evident at 4 th to 5 th week. Osteclast will then turn callus into lamellar bone (Mooney and Siegel, 2005).

RUST examination performed as in the study is non invasive way to examine bone healing process (Kooistra et al., 2010; Hammer et al., 1985; Çekic and Alici, 2013). It was found in the study that the exposure of ELFPEF made bone fracture healing faster than the control group. In the follow-up test, it was found that there were significant differences in RUST values in each week. In the study, it was concluded that exposure to ELF-PEF has been shown to accelerate the healing of bone fractures since the 2 nd week of exposure.

The success of bone healing in delayed union cases is associated with electromagnetic wave stimulation. Electric and electromagnetic fields provide the same stimulation as mechanical stimulation. Mechanical stimulation will cause a change in strain gradient which then causes intersisial fluid movement through canaliculi. The result is an increase in osteocytes. In various in vitro studies, found that the exposure of electric fields causes stimulation of cell proliferation, increases extracellular matrix synthesis and calcification. Electromagnetic stimulation mainly works in osterblast cells and periosteal cells. Electromagnetic stimulation was also

\section{CONCLUSION}

The exposure of ELF-PEF in experimental animals with delayed union fractures can found to significantly increase bone strength due to increased radiological proven calcifications. The study also found that exposure to electromagnetic fields increases prostaglandin and collagen synthesis which causes acceleration of the condrogenesis process. Electromagnetic field stimulation also causes early cartilage formation and an increase in the number of chondrocytes (Victoria et al., 2009; Aaron et al., 2004).

There have been several studies that have directly stimulated electromagnetic waves in fracture bone healing in humans. Research conducted by Shi found that the use of pulsed electromagnetic fields (PEMF) in patients with delayed union of long bone fractures showed significantly better fracture healing than the control group (77.4\% versus 48.1; p 0.029) (Shi et al., 2013). This study supports the previous research (Teven et al., 2012; Einhorn and Gerstenfeld, 2015; Bilezikian and Lawrence, 1996). Similar to previous studies, a 2012 study found that PEMF stimulation in patients with delayd union and non-union tibial fractures caused perfect bone healing at $77.3 \%$ of cases (Assiotis et al., 2012). In a study conducted by Gossling et al., It was shown that PEMF stimulation caused significant non-union bone healing with a cure rate of $81 \%$ (Gossling et al., 1992). Meta analysis found that there were significant differences in fracture healing in the group stimulated by electromagnetic waves compared to those that did not (Aaron et al., 2004).

accelerate the process of bone healing compared to the control group assessed with 
radiology study. The acceleration of bone healing can already be seen from the 2 nd week of exposure. The exposure of ELF-PEF has also

\section{REFERENCES}

Aaron RK, Ciombor DM, and Simon BJ. Treatment of Nonunions with Electric and Electromagnetic Fields. 2004 Clin Orthop Relat Res 419 21-29.

Assiotis A, Sachinis NP, and Chalidis BE. Pulsed electromagnetic fields for the treatment of tibial delayed unions and nonunions. A prospective clinical study and review of the literature. 2012 J Orthop Surg Res 724.

Bilezikian J and LawrenceGR. Rodan GA (ed) Principles of Bone Biology. 2nd ed. 1996. Portland: Academic Press.

Brinker MR and O'Connor DP. The incidence of fractures and dislocations referred for orthopaedic services in a capitated population. 2004 J Bone Joint Surg Am 86-A 290-297.

Çekic E and Alici E. Verification of the reliability of the Radiographic Union Score for Tibial Fractures in the follow-up of patients with tibia corpus fractures operated via the intramedullary nailing technique using the patients' clinical condition. 2013 Injury 44 S8.

Einhorn TA and Gerstenfeld LC. Fracture healing: mechanism and interventions. 2015 Nat Rev Rheumatol 11 45-54.

$\mathrm{Fu}$ YC, Lin CC, Chang JK, Chen CH, Tai IC, Wang JW, et al. A novel single pulsed electromagnetic field stimulates been shown to accelerate bone healing radiologically in each week of administration.

osteogenesis of bone marrow mesenchymal stem cells and bone repair. 2014 PloS One 9 e91581.

Ganveer GB and Tiwari RR. Injury pattern among non-fatal road traffic accident cases: a cross-sectional study in Central India. 2005 Indian J Med Sci 59 9-12.

Gao F, Lv TR, Zhou JC, and Qin XD. Effects of obesity on the healing of bone fracture in mice. 2018 Journal of Orthopaedic Surgery and Research 13145.

Giannoudis PV, Einhorn TA, and Marsh D. Fracture healing: the diamond concept. 2007 Injury 38 S3-S6.

Giannoudis PV, Einhorn TA, Schmidmaier D, and Marsh D. The diamond conceptopen questions. 2008 Injury 39 S5S8.

Gossling HR, Bernstein RA, and Abbott J. Treatment of ununited tibial fractures: A comparison of surgery and pulsed electromagnetic fields (PEMF). 1992 Orthopedics 15 711-719.

Hammer R, Hammerby S, and Lindholm B. Accuracy of radiologic assessment of tibial shaft fracture union in humans. 1985 Clin Orthop Relat Res 199233 238.

Kooistra BW, Dijkman BG, Busse JW, Sprague S, Schemitsch EH, and Bhandari M. The Radiographic Union Scale in Tibial Fractures: Reliability and 
Validity. 2010 J Orthop Trauma 24 S81-S86.

Lu C, Miclau T, Hu D, and Marcucio RS. Ischemia leads to delayed-union during fracture healing: a mouse model. 2007 J Orthop Res 25 51-61.

Marcelini S, Henriquez JP, and Bertin A. Control of osteogenesis by the canonical Wnt and BMP pathway in vivo. 2012 Bioessay 34 953-962.

Mooney MP and Siegel MI. Animal models for bone tissue engineering of criticalsized defects (CSDs), bone pathologies, and orthopedic disease states. In: Hollinge JO, Einhorn TA, Doll BA, Sfeir C, editors. Bone tissue engineering. 2005. Boca raton: CRC Press. 217-244.

Ongaro A, Pellati A, Bagheri L, Fortini C, Setti $S$, and De Mattei M. Pulsed Electromagnetic Fields Stimulate Osteogenic Differentiation in Human Bone Marrow and Adipose Tissue Derived Mesenchymal Stem Cells. 2014 Bioelectromagnetics 35 426436.

Phieffer LS and Goulet JA. Delayed unions of the tibia. 2006 Instr Course Lect 55 389-401.

Riyadina W, Suhardi, and Permana M. Pola dan Determinan Sosiodemografi Cedera Akibat Kecelakaan Lalu Lintas di Indonesia. 2009 Maj Kedokt Indon 59 464-472.

Shi HF, Xiong J, Chen YX, Wang FJ, Qiu XS, Wang YH, et al. Early application of pulsed electromagnetic field in the treatment of postoperative delayed union of long-bone fractures: a prospective randomized controlled study. 2013 BMC Musculoskeletal Disord. 1435.

Shirley D, Marsh D, Jordan G, McQuaid S, and Li G. Systemic recruitment of osteoblastic cells in fracture healing. 2005 J Orthop Res 23 1012-1021.

Singer BR, McLauchan GJ, Robinson CM, and Christie J. Epidemiology fractures in 15.000 adults : the influence of age and gender. 1998 J Bone Joint Surg (Br). 80 243-248.

Teven CM, Greives M, Natale RB, Su Y, Luo $\mathrm{Q}, \mathrm{He} \mathrm{BC}$, et al. Differentiation of osteoprogenitor cells is induced by high frequency pulsed electromagnetic field. $2012 \mathrm{~J}$ Craniofac Surg 23 586-593.

Utvåg SE, Grundnes O, Reikeras O. Effects of periosteal stripping on healing of segmental fractures in rats. $1996 \mathrm{~J}$ Orthop Trauma 10 279-284.

Victoria G, Petrisor B, Drew B, and Dick D. Bone stimulation for fracture healing: What's all the fuss? 2009 Indian $J$ Orthop 43 117-121 